\title{
Book Review Creators
}

Book Review of

Creators by Paul Johnson (2006) Harper Collins Publishers, USA, pp. 320.

"How can somebody so smart be so deucedly dumb?" This new book by the always readable and always intelligent Mr. Paul Johnson brought back my father's words, as vivid now as when he would occasionally admonish me with them when I had done some boneheaded thing in boyhood. Reading it, one finds that even great Creators, as the author calls his subjects, were boneheads once in a while...and sometimes worse!

In succinct, informative and often amusing fashion, the backgrounds of an interesting facts about seventeen famous individuals of diverse creativity are presented: Geoffrey Chaucer, Albrecht Durer, William Shakespeare, J.S. Bach, J.M.W. Turner, Hokusai, Jane Austen, A.W.N. Pugin, Euene Viollet-le-Duc, Victor Hugo, Mark Twain, Louis Comfort Tiffany, T.S. Eliot, CristObal Balenciaga, Christian Dior, Pablo Picasso, and Walt Disney.

All of them gained admiration for their extraordinary creativity, to say nothing of their prolificness. "Creators" without a doubt they were, but the book does not solve the mystery of what created "creativity". Some -called creativity goes nowhere, such as that of the Parisian jewellers of the nineteenth century who tried to sell rings for the divorced, to be given in a ceremony involving a divorce cake and a divorce reception. Obviously, some buffoonery succeeds, and some does not, but a fuss is usually made over great productivity, even when we are unsure of just what it is all about.

Mr. Johnson links creativity with courage, and this rings true. A creator sees something that no one else sees, and then goes and does something about it, and this displays courage to a greater or lesser degree. Persistence, if not obsessiveness, is another trait common to the creative person, and the subjects of the book show a great deal of it. I can't help but conclude that these individuals were helped in the persistence of their creativity by the fact that they were not distracted by an electronic mass-culture that dulls and stultifies the mind and the energies, killing the possibility of creativity. Most of the "Creators" in the book were, all In all, pretty admirable characters, regardless of their personal foibles, with the exception of two-Hugo and Picasso.

Victor Hugo was called a "genius without a brain". Incredibly verbal and prolific, he seems never to have shut up! He became a noisy politician, a French jingoist and, toward the end of his life, a self-absorbed dirty old man. Jules Melamitire is quoted as having said of Hugo in 1889, "This man may have genius; you may be sure he is nothing else?'

Only in comparison to such a monster as Pablo Picasso could Hugo seem admirable. In the course of his chequered career of fraud and imposture, Picasso moved from pro-Nazi collaboration in occupied Paris to fawning sycophancy of Stalin later on, painting a portrait of the dictator in 1953. (The Communists, to their credit, were not impressed. "Socialist realism", with all its limitations, was at least better than Picassoism.) Leading a corrupt and repulsive personal life while fooling and beguiling the art "critics" and the public mass media, his "creativity" was sufficient to gain him many millions of dollars in the course of his seemingly inter-

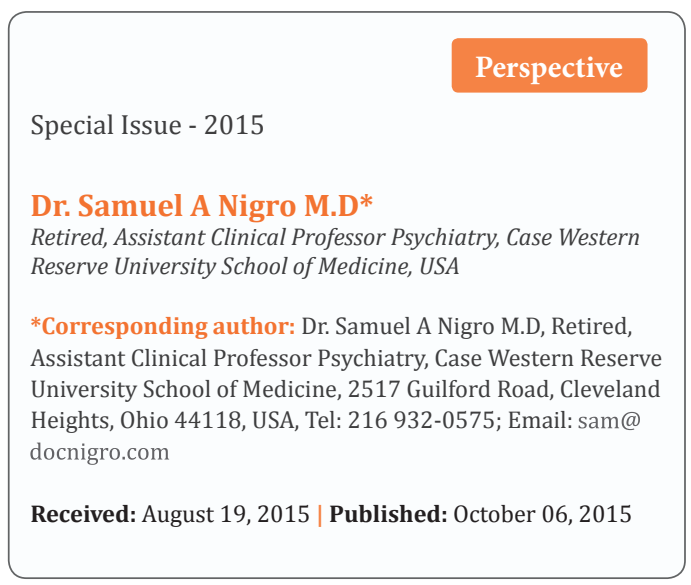

minable existence of 92 years.

Much can be learned from Mr. Johnson's book: it is great fun to read, extremely informative, and itself a "creative" approach to informing the world of what it should know regarding these "Creators". But the mystery of creativity remains; the book is not a "how-to" volume. We can only be glad that creators do occasionally blossom forth and admire their productions when those are actually and truly admirable. 